Supporting Information for

\title{
Heteroatom Bridging Strategy in Carbon-based Catalysts for Promoted Oxidative Desulfurization Performance
}

\author{
Peiwen $\mathrm{Wu}^{\mathrm{a}}$, Yang Sun ${ }^{\mathrm{a}}$, Linlin Chen ${ }^{\mathrm{a}}$, Qingdong $\mathrm{Jia}^{\mathrm{a}}$, Jing $\mathrm{He}^{\mathrm{a}}$, Wenhui Ma ${ }^{\mathrm{a}}$, Linjie $\mathrm{Lu}^{\mathrm{a}}$, \\ Yanhong Chao ${ }^{a}$, Lei Fan ${ }^{\mathrm{b}}$, Wenshuai Zhu, *
}

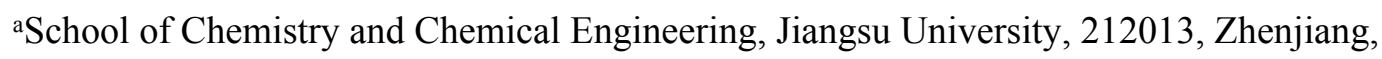
China

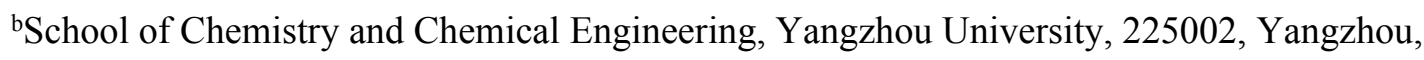
China

Email: zhuws@ujs.edu.cn



Fig. S1 a) TEM image of 3B-G; b) magnified TEM image of 3B-G. 




Fig. S2 Pore size distribution of all catalysts. 